\title{
Influence of Sludge Compost on Soil Properties and Tomato Plant Uptake of Metals
}

\author{
Mai M Al Saadii ${ }^{1}$, Malik M Al Wardy ${ }^{2 *}$ \\ ${ }^{1}$ Department of Engineering, Al Musanna College of Technology, Oman \\ ${ }^{2}$ Faculty of soil and water management, Sultan Qaboos University, Oman \\ *Corresponding author: Malik M Al Wardy, Agriculture of college, Faculty of soil and water management, Sultan Qaboos University, \\ Oman \\ To Cite This Article: Malik M Al Wardy. Influence of Sludge Compost on Soil Properties and Tomato Plant Uptake of Metals. Am J Biomed Sci \& \\ Res. 2019 - 2(2). AJBSR.MS.ID.000579. DOI: 10.34297/AJBSR.2019.02.000579
}

Received: March 28, 2019 | Published: April 04, 2019

\begin{abstract}
The Sultanate of Oman is one of the countries that are hamstrung by scarcity of water. This is, obviously, a problem limiting the production of crops. Oman, therefore, needs to leverage the wastewater that is produced in the sewage system. Moreover, Wastewater Company, Haya, converts the biosolid output of the wastewater processing into composting process. But unfortunately, this type of soil amendment is likely to contain various toxic materials. Therefore, it is important to identify the forms of various metals such as $\mathrm{Mg}, \mathrm{Ca}, \mathrm{Al}, \mathrm{Zn}, \mathrm{Cu}, \mathrm{Co}, \mathrm{Cr}, \mathrm{As}, \mathrm{Cd}, \mathrm{Fe}, \mathrm{Mn}$ and $\mathrm{Ni}$, etc. which could exist in the soil as a result of the application of sludge fertilizer to land - so as to enable us to spot their existence as also to evaluate the extent of their movement. It could also help us determine the bioavailability and toxicity of these metals. Chemical fractionation is a chemical process used to identify the metal fractions in soil samples or in sediment.
\end{abstract}

The sequential extraction technique has been used for this purpose and it has been revealed that some metals could bind with different materials and compounds in soil such as carbonate, iron oxide, manganese and organic matter. The presence of metals fractions in Omani soil and nutrients like Mg and Ca was studied; it had found that Ba was appeared as exchangeable in columns which were amended with $34.8 \mathrm{~g} / \mathrm{kg}$ and other elements like $\mathrm{Al}, \mathrm{Ni}$. Na and $\mathrm{Zn}$ were available as organic fractions, but $\mathrm{Ca}$ and $\mathrm{Mg}$ were available in all types of fractions. The rest of the metals were not strong enough to appear due to the weakness of the extract solution and high rate of $\mathrm{pH}$.

Besides, most of the fractions were found to be more in columns irrigated at a rate of $60 \mathrm{ml} / \mathrm{min}$ than $120 \mathrm{ml} / \mathrm{min}$. The plant uptake of metals was studied as well, and it was found that the roots of the tomato plant recorded a high concentration of elements compared to the fruit, leaves and stem. The study also found that the metals had accumulated in the order of root, fruit, leaves and stem. And that may interpret as metals translocation from lower parts to upper parts. Moreover, compost addition increased the yield of tomato plants in terms of height of stems and the weight of biomass of tomato organs.

\section{Introduction}

Most countries tend to use treated sewage sludge in agricultural lands as a way of increasing their fertility. The result would be an uptick in production owing to the presence of essential micronutrients for growth like zinc, iron and copper. Municipal sewage sludge is a byproduct of wastewater biological treatment carried out through activated sludge method or bio-film method. This byproduct goes through composting process or fermentation biotechnology process for its conversion into compost. This is done by mixing it with organic materials like woods in a bid to reduce their biological risk and boost their resistance against diseases [1].

Sludge compost can supply the land with humus capable of controlling heavy metals in soil through adsorption or forming stable complexes with humid substances [2]. Besides, the humus material can hold water and positive ions so the plant takes root easily; As a result, water retention and plant growth would be beefed up. Moreover, the use of compost increases soil porosity which, in turn, would improve structural stability and reduce soil erosion [5]. The application of organic amendment like sewage sludge compost affects the physic-chemical properties by way of increasing the content of organic matter, total nitrogen content and electrical conductivity even as it causes reduction in $\mathrm{pH}$, though slightly. Electrical conductivity could increase with sewage sludge compost application as a result of acidification in combination with subsequent solubility of metallic elements, something which can increase the presence of salts.

Sludge compost has environmental risk arising from the potential addition of metals like cadmium, copper and zinc. However, organic matter tends to decrease metals concentration 
through the formation of complexes in the form of insoluble organometallic complex; therefore, their mobility and phytotoxicity will be less [7]. It is certainly good to have more studies about metal fractions in a bid to confirm that the addition of compost would provide exchangeable fraction for metals and this is very important for plant uptake, especially with reference to the Omani soil.

\section{Objectives}

To study heavy metals fractions in calcareous soils amended with sewage sludge compost

a. To evaluate the influence of sewage sludge compost rates on soil properties and nutrients availabilities,

b. To describe the change in the distribution of nutrients with depth through soil column after the addition of sewage sludge compost, and

c. To quantify tomatoes plant uptake for different nutrients.

\section{The Hypothesis}

Soils in Oman are classified as calcareous owing to the availability of calcium and magnesium carbonates in large amounts. Calcareous soils contain low amounts of heavy metals. Also, organic amendment can reduce heavy metals availability in soil through adsorption process or by the formation of stable complexes with humid substance [2]. The bioavailability and the toxicity of heavy metals for plant can be high if they are added to soils as soluble salts compared to that released from or added from biosolids [3].

\section{Importance of the study}

Application of organic amendment like sewage sludge compost to agricultural lands in order to increase their production has been studied in terms of organic matter content, moisture content and nutrients availability for plant growth. Indeed, these kinds of composts have contained different types of elements at various doses which could cause clinic problems for human beings, plants and animals. Therefore $\mathrm{Mg}, \mathrm{Ca}, \mathrm{Al}, \mathrm{Pb}, \mathrm{Zn}, \mathrm{Cu}, \mathrm{Co}, \mathrm{Cr}, \mathrm{As}, \mathrm{Cd}, \mathrm{Fe}, \mathrm{Mn}$ and $\mathrm{Ni}$ are selected to investigate their availability in the tomato plant and soil after organic amendment application because they have a considerable impact on plant growth.

\section{Methodology}

\section{Experimental design}

The treated sewage sludge compost used in the study was provided graciously by Haya. It was a single batch which contained $50 \mathrm{~L}$ (approximately $25 \mathrm{~kg}$ ) of Kala compost. (Kala is the brand name of treated compost). The experiment involved two sewage sludge compost rates $(0 \mathrm{~g} / \mathrm{kg}$ (control), $17.4 \mathrm{~g} / \mathrm{kg}$ and $34.8 \mathrm{~g} / \mathrm{kg}$ or $0 \mathrm{t} / \mathrm{h}-1,6$ t/ha- 1 and $12 \mathrm{t} / \mathrm{h}-1)$ and two irrigation rates $2 \mathrm{~mm} /$ day $(0.06 \mathrm{~L} /$ $\mathrm{min})$ and $4 \mathrm{~mm} /$ day $(0.120 \mathrm{~L} / \mathrm{min})$. Each sludge compost rate had three replicates with both irrigation rates which were represented in line 1 and line 2 . The totals of columns were eighteen and they were randomly distributed within two lines as shown in following flowchart (Figure 1).

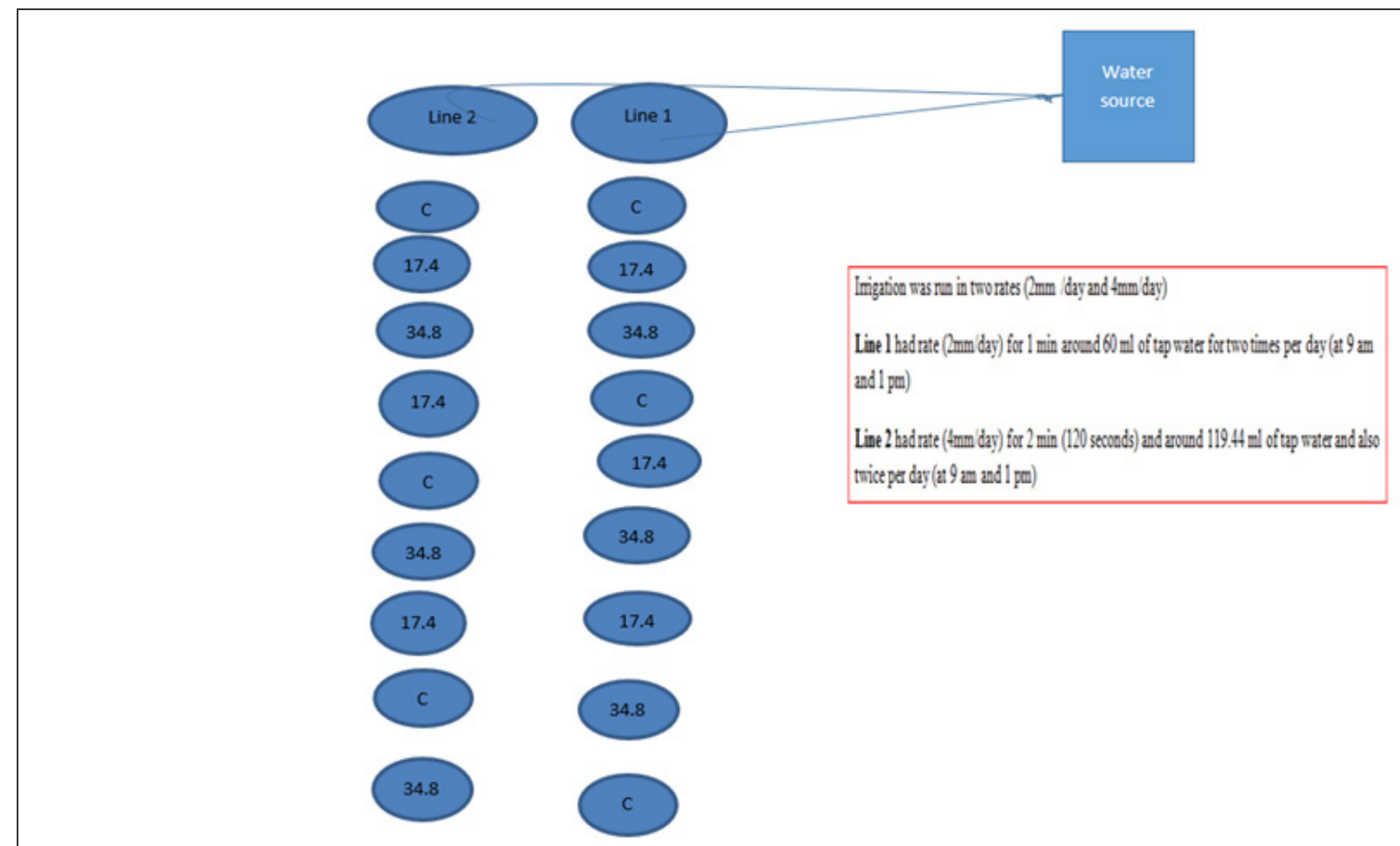

Figure 1: Mapping of soil columns sets in green house.

\section{Experiment in green house}

The temperature was adjusted in the range of 20-25 degree Celsius. Eighteen columns were filled with air-dried soil and they were distributed into lines. Line one contained nine columns of three different rates of sludge compost, and it was the same for line 2 with a difference in irrigation rates for both lines. The columns were randomly arranged and then one tomato tree was planted in each column. The drip irrigation system was turned on to maintain water content for plant growth and the growth was monitored until the harvesting stage. Then the soil and plant samples were carried to laboratory for chemical and physical properties analysis (Figure 2). 


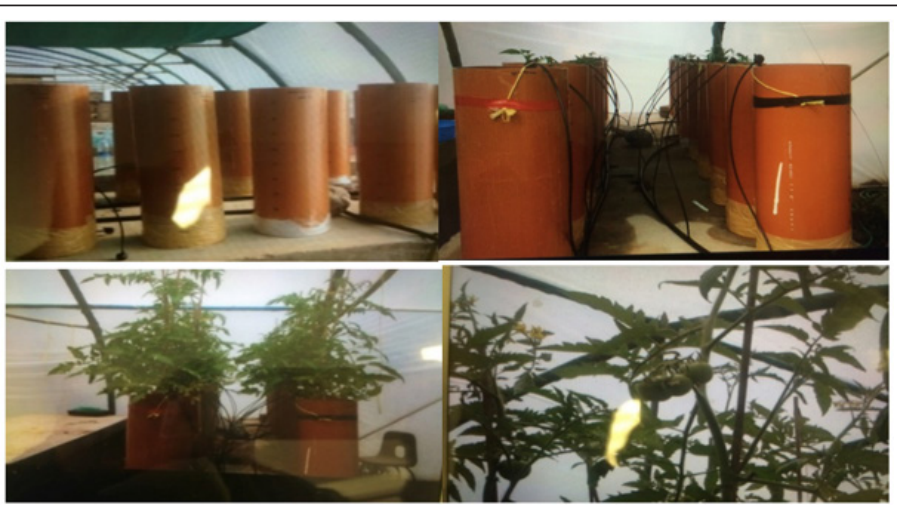

Figure 2: The setup of experiment in greenhouse.

\section{Collection and preparation of soil samples}

Soil samples were collected from Area No.4 in a farm at the agricultural experimental station, SQU. Collected soils were dried and then sieved with a $2 \mathrm{~mm}$ sieve. About $16.675 \mathrm{~kg}$ of soil was packed in each $50 \mathrm{~cm}$ column and exactly up to $40 \mathrm{~cm}$. The first
$10 \mathrm{~cm}$ of the column was left for plant growth purpose. A mixture of soil and compost was added at the second $10 \mathrm{~cm}$ of the column to be in the ratio of 1:3 of compost / soil. The last two depths of the column were filled with plain soil (Figure 3).

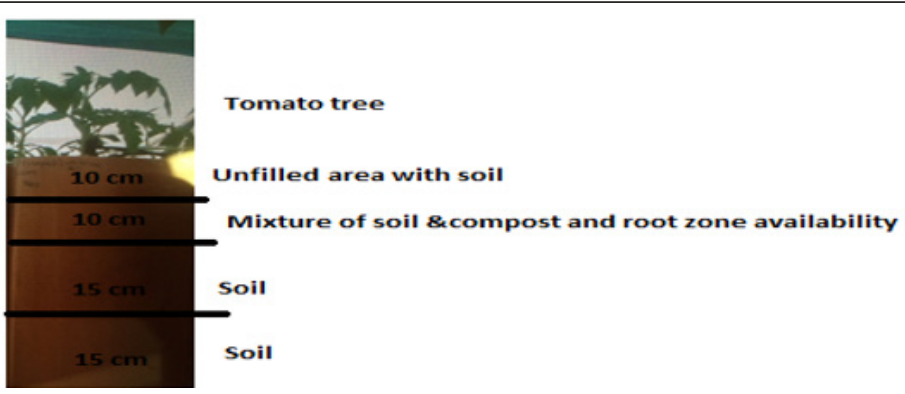

Figure 3: Soil column depths with tomato plant.

\section{Physical and chemical analysis}

Physical and chemical tests for soil samples were done to measure $\mathrm{pH}$ and electrical conductivity, water content, organic matter, soil texture and CaCO3. The analysis had included metals fractionation in soil samples at different depths of soil column (1020, 20-35 and 35-50 cm). Moreover, plant uptake for metals was investigated and total metal concentration was studied by using ICP-AES.

\section{Plant analysis}

Tomato plant organs were separated. The shoots had been dried at $70 \mathrm{oC}$ in the oven and the rest like leaves; stem and root were air-dried for around eight days. Then they were ground to be used for analysis weight. Two grams of each part of the tomato plant sample were transferred to a $50 \mathrm{ml}$ digestion tube. $10 \mathrm{ml}$ of mixed concentrated acids (500 ml nitric acid, $100 \mathrm{ml}$ perchloric acid and $50 \mathrm{ml}$ sulfuric acid) was added. Digestion tubes were transferred to a digestion instrument and turned on at $120 \mathrm{oC}$ for hour or until the color of the samples was changed to yellowish or transparent. The samples were taken out from the digestion instrument and left to cool. Whatman (No.41) filter papers with funnels were prepared on the $50 \mathrm{ml}$ volumetric flask. All the contents of the tube were poured into $50 \mathrm{ml}$ volumetric flask and the tube was washed with distilled water and poured into the flask until the mark. The extractant could be used to determine $\mathrm{Ca}, \mathrm{Na}, \mathrm{Mg}, \mathrm{K}, \mathrm{CO} 3, \mathrm{HCO} 3, \mathrm{P}, \mathrm{Mn}, \mathrm{Zn}, \mathrm{Cu}$ and $\mathrm{Fe}$.

\section{The sequential extraction technique}

The sequential extraction technique (based on Tessier et al., 1979) was performed to extract different metals fractions. Exchangeable fraction was extracted by taking one gram of soil and transferring to $50 \mathrm{ml}$ polypropylene centrifuge tubes. The sample was extracted with $8 \mathrm{ml}$ of $1 \mathrm{M} \mathrm{MgCl} 2$ (extract 1) at room temperature with continuous agitation around one hour.

Carbonate fraction extraction was done by taking the residue from exchangeable fraction then extracted with $8 \mathrm{ml}$ of $1 \mathrm{M} \mathrm{NaOAc}$ (pH5) (extract 2) and was adjusted by acetic acid for one hour at room temperature with continuous agitation. Fe-Mn oxides fraction was affected by taking the residue from carbonate and then extracted with $20 \mathrm{ml}$ of $0.04 \mathrm{M} \mathrm{NH20H.HCL}$ in $25 \%(\mathrm{v} / \mathrm{v}$ ) HNO3 (extract 3) which was agitated continuously for five hours at $80 \mathrm{oC}$ in a shaker (IKAISS $4000 \mathrm{i}$ control).

Organic fraction was done by taking the residue from previous stage and the extracted with $3 \mathrm{ml}$ of $0.02 \mathrm{M} \mathrm{HNO3}$ and $8 \mathrm{ml}$ of $30 \% \mathrm{H} 2 \mathrm{O} 2$ ( $\mathrm{pH} \mathrm{2}$ ) (extract 4) and adjusted by HNO3 occasionally and agitated for five hours at $80 \mathrm{oC}$. After cooling $5 \mathrm{ml}$ of $3.2 \mathrm{M}$ NH4OAc in $20 \%$ (v/v) HNO3 was diluted to $20 \mathrm{ml}$ and continuously agitated at room temperature for 30 minutes. $50 \mathrm{ml}$ Polypropylene centrifuge tubes were used to minimize the loss of the extractant and soil sample at each step. 

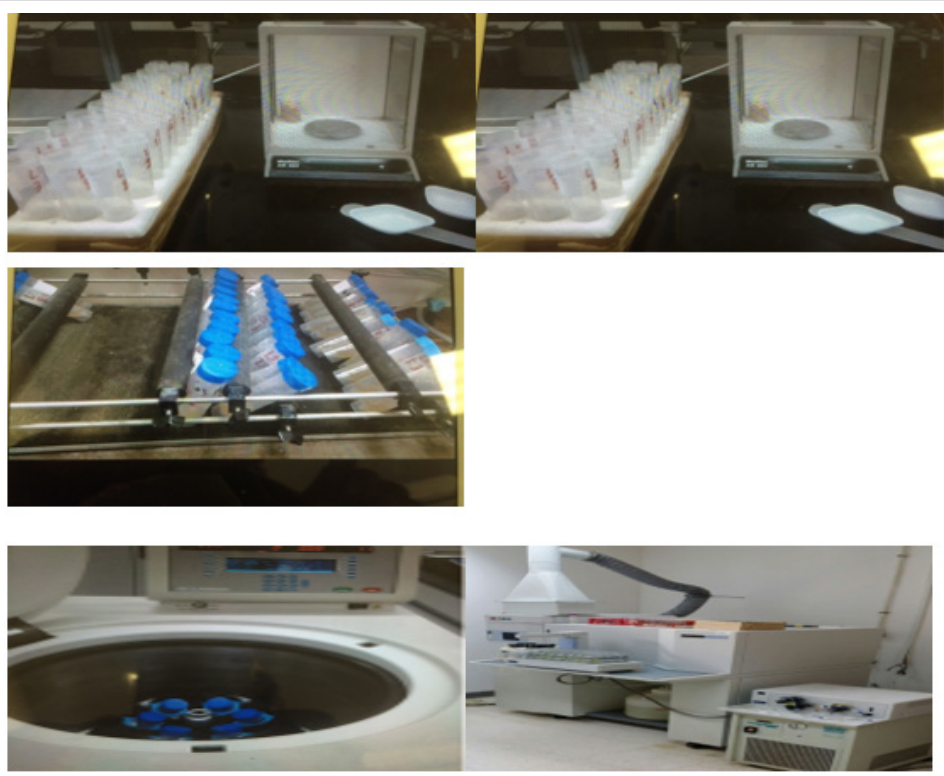

Figure 4: The setup of chemical fractionation experiment for metal in soil samples.

All extracts were centrifuged at $7000 \mathrm{rpm}$ for 20 minutes for separation of each fraction and they were taken for analysis using ICP-AAS for trace metals concentrations (Figure 4).

\section{Total heavy metal concentration extraction}

One gram of oven-dried soil was weighed and recorded, and it was then transferred to a digestion tube. $10 \mathrm{ml}$ hydrochloric acid was added to the soil sample and put into a digestion apparatus at $100 \mathrm{oC}$ to remain there for one hour. The extractant was left to cool and then filtered with Whatman filter paper $41 \mathrm{~mm}$ into 25 $\mathrm{ml}$ volumetric flasks. The filtrate was diluted up to the mark of volumetric flask. Finally, it was transferred to ICP tubes for analysis.

\section{Statistical Methods}

Paired and unpaired t-test through excel Microsoft program, Duncan's multiple-range test $(\mathrm{p}=0.05)$ or $(\mathrm{p}>0.05)$ was carried out to indicate significant difference in the physic-chemical properties in soil column depths (10-20, 20-35.35-50 cm). Means comparison was used in the statistical analysis for total concentration of metals in the soil and tomato plant. Correlation test was applied to test the relation among metals concentration in soil depths with composts rates by recording their positive and negative values.

\section{Results}

\section{Soil physical-chemical properties}

Soil and compost samples were stored after collection at room temperature $(25 \mathrm{oC})$ in the research soil laboratory at the soil and water management department in Agricultural College for chemical and physical analysis. The analysis was carried out using different instruments and apparatuses. Muffle furnace (size 2. Gallenkamp) was used for organic matter content analysis, Oven (Merit) was used for moisture content and $\mathrm{pH}$, electricity conductivity meters (Thermo Scientific Orion4-star) for pH and EC. It was done for both soil and compost samples and the results were listed in Table1. The results showed that the soil is basic according to $\mathrm{pH}$ value in the below table with little presence of salts which were shown through EC values. In addition, the soil samples contained less water moisture content as well as organic matter. Regarding the compost which tended to be neutral in its $\mathrm{pH}$, it contained higher amounts of salts compared to soil samples; even organic matter and moisture content were higher in compost compared to soil. It follows then that the addition of compost to soil can increase organic matter.

\begin{tabular}{|l|l|l|}
\hline \multicolumn{3}{|l|}{ Table 1: Initial Soil and sludge compost physic- chemical properties. } \\
\hline Parameter & Soil & Sewage sludge compost \\
\hline Soil texture & Sandy loam & - \\
\hline pH & 8.3 & 7.00 \\
\hline EC & $336.6-418 \mu \mathrm{S} / \mathrm{cm}$ & $8470-9480 \mu \mathrm{S} / \mathrm{cm}$ \\
\hline Moisture content & $3.09 \%$ & $32.98-32.63 \%$ \\
\hline Organic content & $3.23 \%$ & $49-52 \%$ \\
\hline $\mathrm{CaCO}_{3}$ & $38 \%-50 \%$ & - \\
\hline
\end{tabular}

Organic matter contains a type of substance called humus which could increase nutrient by attacking positive ions. Humus could also hold water and increase its content in soil, something which had been reported by, and besides, soil water retention was found to go up (Table 1).

\section{Paired and Unpaired t-Test: Two-Sample Assuming Unequal Variance}

The effect of compost addition on soil samples per depth had been investigated by studying the change in physical-chemical properties which could occur when soil was amended with two different compost rates $(17.4 \mathrm{~g} / \mathrm{kg}$ and $34.8 \mathrm{~g} / \mathrm{kg})$. In Table 2 , the results of physical and chemical analysis for soil samples per depth were shown. The statistical analysis, exactly paired and unpaired $t$-test through $p$ value $(p=0.05$ or $p>0.005$ ) was done to find out the significant difference among the values. The highlighted values of soil properties in the below table would bring out significant difference among soil properties per depth. 


\begin{tabular}{|c|c|c|c|c|c|c|c|c|c|}
\hline Rate & Depth & Line $1 * \mathrm{pH}$ & Line $2^{* *} \mathrm{pH}$ & Line 1 EC & $\begin{array}{l}\text { Line } 2 \text { EC } \\
(\mu \mathrm{S} / \mathrm{cm})\end{array}$ & Line1 MC\% & $\begin{array}{ll}\text { Line } & 2 \\
\text { MC\% } & \\
\end{array}$ & line $10 \mathrm{M} \%$ & $\begin{array}{l}\text { Line } \\
\text { OM\% }\end{array}$ \\
\hline & $(\mathrm{cm})$ & & & $(\mu \mathrm{S} / \mathrm{cm})$ & & & & & \\
\hline \multirow[t]{3}{*}{ Control } & $10-20$ & $8.1^{\mathrm{a}}$ & $8.2^{\mathrm{a}}$ & $312^{\mathrm{a}}$ & $256^{\mathrm{ab}}$ & $3.75^{a}$ & $5.19 \mathrm{ab}$ & $2.06^{\mathrm{ab}}$ & $2.67^{a}$ \\
\hline & $20-35$ & 8.17 a n & $8.2^{\mathrm{a}}$ & $191^{a}$ & $250^{\mathrm{bc}}$ & $2.16^{\mathrm{a}}$ & $3.39^{\mathrm{a}}$ & $2.35^{\mathrm{a}}$ & $3.72^{a b}$ \\
\hline & $35-50$ & $8.17^{n}$ & $8.37^{\text {a }}$ & $233^{\mathrm{ad}}$ & $524^{\mathrm{cd}}$ & $4.21^{\mathrm{a}}$ & 7 ba & $2.01^{\mathrm{b}}$ & $4.43^{a}$ \\
\hline \multirow[t]{3}{*}{$17.4 \mathrm{~g} / \mathrm{kg}$} & $10-20$ & $8.2^{\mathrm{a}}$ & $8.27^{\text {a }}$ & $304^{\mathrm{a}}$ & $413^{a}$ & $3.53^{\text {a }}$ & $2.82^{\mathrm{a}}$ & $1.56^{\mathrm{a}}$ & $1.59^{\text {a }}$ \\
\hline & $20-35$ & 8 & $8.23^{a}$ & $258^{a}$ & $323^{a}$ & $4.14^{\mathrm{ac}}$ & $2.81^{\mathrm{ac}}$ & $1.78^{\text {a }}$ & $2.69^{a}$ \\
\hline & $35-50$ & $8.1^{\mathrm{a}}$ & $8.3^{a}$ & $303^{a}$ & $354^{\mathrm{a}}$ & $7.47^{\mathrm{a}}$ & $5.39^{a}$ & 2.92 ba & $3.58^{\mathrm{a}}$ \\
\hline \multirow[t]{3}{*}{$34.8 \mathrm{~g} / \mathrm{kg}$} & $10-20$ & $8.13^{a}$ & $8.13^{a}$ & $172^{\mathrm{a}}$ & $369^{a}$ & $4.19^{a}$ & $5.03^{a}$ & $2.31^{\mathrm{a}}$ & $2.6^{a}$ \\
\hline & $20-35$ & $8.17^{\text {a }}$ & $8.17^{\text {a }}$ & $166^{\mathrm{a}}$ & $300^{a}$ & $5.61^{a}$ & $5.71^{\mathrm{a}}$ & $2.02^{a}$ & $1.18^{b}$ \\
\hline & $35-50$ & $7.93 \mathrm{ab}$ & $8.33^{a b}$ & $187^{\mathrm{ad}}$ & $497^{a}$ & $5.06^{\mathrm{ad}}$ & $4.35^{\mathrm{ad}}$ & $3.24^{\mathrm{a}}$ & $2.86^{a}$ \\
\hline
\end{tabular}

Table 2 showed there was significant difference in $\mathrm{pH}$ values in columns amended with $34.8 \mathrm{~g} / \mathrm{kg}$ which were irrigated with both irrigation rates. The values were: 7.93 in line 1 and 8.33 in line 2 . The results prove that compost addition to soil cause reduction in $\mathrm{pH}$ [2] because of acids availability like fulvic, carboxylic and humic acids in line 1, Furthermore, minerals solubility with application of more water leads to increase in $\mathrm{pH}$ values in line 2 . The significant difference for EC values was in the last depth of soil column with compost rate $34.8 \mathrm{~g} / \mathrm{kg}$ and $0 \mathrm{~g} / \mathrm{kg}$ in line 1 and the values were 187 and $233 \mu \mathrm{S} / \mathrm{cm}$ respectively. Also, it was in control columns within soil depths in line 2 as a result of high mineral solubility and accumulation of salts in the last depths of columns. Also, [7] stated that electrical conductivity increases when sludge compost is applied to soil. There was significant difference in MC values between line 1 and line 2 at the second depth of soil column with a compost rate of $17.4 \mathrm{~g} / \mathrm{kg}$ and the values were $4.14 \%$ and $2.81 \%$, respectively.

With compost rate of $34.8 \mathrm{~g} / \mathrm{kg}$ the values were $5.06 \%$ in line 1 and $4.35 \%$ in line 2 . Also, in line 2 within controls column between the first and the last depths the values were $5.19 \%$ and $7 \%$ respectively. The decrease in MC may be because of the soil structure which was sandy loam or with porosity availability as a result of compost availability in addition to the consumption of water by dry compost. Regarding OM values there was significant difference in the last depth of soil column with the compost rate of $17.4 \mathrm{~g} / \mathrm{kg}$ and $0 \mathrm{~g} / \mathrm{kg}$ and the values were 2.92 and $2.01 \%$ respectively. There was also notable difference within the control column in line 1 between the first and the last depths (2.06 and $2.01 \%$ ). Compost rate of $34.8 \mathrm{~g} / \mathrm{kg}$ recorded significant difference with control in second depth (1.18 and 3.72\%) and the reason for the high organic matter content was the availability of root residues as it was going down in soil depths.

\section{Total concentration of elements in soil sample}

Amended and unamended soil samples per depths were analyzed to find out the concentration of metals like $\mathrm{Al}, \mathrm{Fe}, \mathrm{Cr}, \mathrm{Co}$, $\mathrm{Zn}, \mathrm{Pb}, \mathrm{Mn}, \mathrm{Ni}$, Ti and $\mathrm{Cu}$. The digestion method was followed, i.e.., by adding concentrated $\mathrm{HCl}$ to soil samples to release the metals from the soil so they can be detected by ICP-AAS. The metals were present in $\mathrm{ml} / \mathrm{kg}$ in the soil solution, but the concentrations were converted to $\mathrm{mg} / \mathrm{kg}$ in solid soil. Also it will indicate to the safe concentration of metals in amended soil that is postulated by the Environment Ministry. In the following context and graphs, the total concentration of metals in soil samples per depth was compared between control columns and amended columns with compost rates of $17.4 \mathrm{~g} / \mathrm{kg}$ and $34.8 \mathrm{~g} / \mathrm{kg}$; it was found that different metals were available at various concentrations in amended and unamended columns.

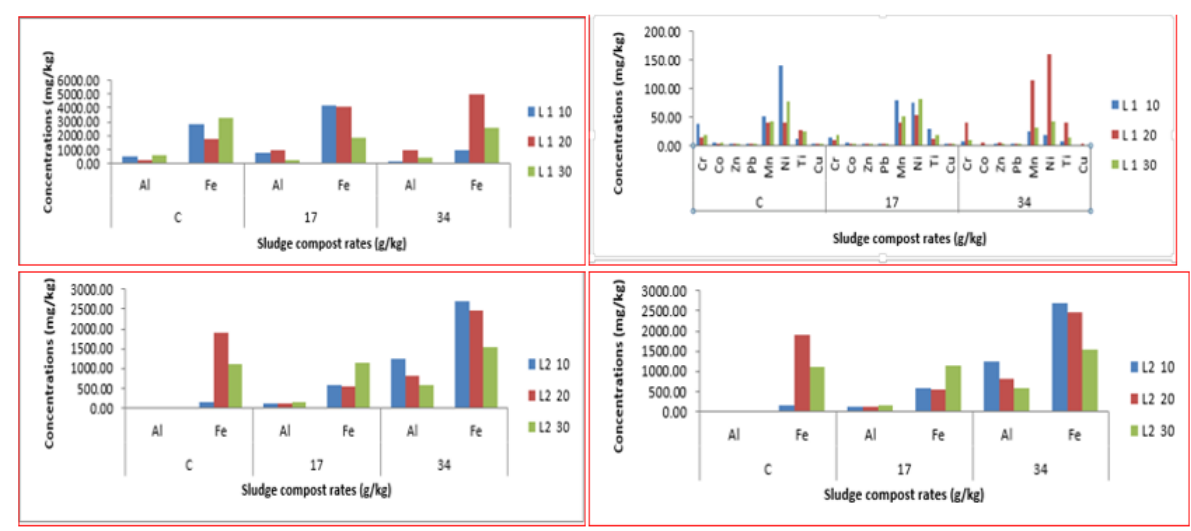

Figure 5: Total concentration of elements in soil samples at different rates of compost in the different soil depths with $60 \mathrm{ml} / \mathrm{min}$ irrigation rate and $120 \mathrm{ml} / \mathrm{min}$ irrigation rate. 
$\mathrm{Al}, \mathrm{Fe} \mathrm{Cr}, \mathrm{Co}, \mathrm{Zn}, \mathrm{Pb}, \mathrm{Mn}, \mathrm{Ni}, \mathrm{Ti}$ and $\mathrm{Cu}$ concentration increased with $0 \mathrm{~g} / \mathrm{kg}$ and decreased with $34.8 \mathrm{~g} / \mathrm{kg}$ as these metals were going down in soil column depths because these are integral elements of soil composition as it was shown in control columns. Moreover, they were taken in by the plant root in the column amended with $34.8 \mathrm{~g} / \mathrm{kg}$ of compost and that caused reduction in their concentration as it was shown through the correlation test for soil samples in that column. Moreover, perhaps those metals were bound to organic materials, especially humus, something which is good to control the availability of metals in soil through adsorption or by forming stable complexes with humid substances [2]. The concentrations of metals in line 1 were higher compared to line 2 because more water led to increase in the leaching of metals from the soil column. $\mathrm{Al}, \mathrm{Fe}, \mathrm{Cr}, \mathrm{Zn}, \mathrm{Pb}, \mathrm{Mn}, \mathrm{Ni}$ and $\mathrm{Ti}$ concentration increased with $0 \mathrm{~g} / \mathrm{kg}$ and $17.4 \mathrm{~g} / \mathrm{kg}$ but they were decreasing with $34.8 \mathrm{~g} / \mathrm{kg}$ except $\mathrm{Cu}$ which increased as these elements were going down in soil column depths (Figures 5). These metals were integral elements of soil composition as it was shown in control columns, and they were taken in by the tomato root which, in turn, led to the decrease in their concentrations in columns amended with $34.8 \mathrm{~g} / \mathrm{kg}$. Hence irrigation rate $120 \mathrm{ml} / \mathrm{min}$ recorded reduction in metals concentration in columns which were unamended (control columns) and amended with $17.4 \mathrm{~g} / \mathrm{kg}$ (due to the leaching factor).

The influence of compost addition to soil samples was clear through comparison between metals concentration within different soil depths (refer to the below tables). It was found that metals were available in compost samples and amended and unamended samples in different amounts, but their concentrations were decreasing and increasing as they went down in soil depths. Hence, $\mathrm{Al}, \mathrm{Cr}, \mathrm{Fe}, \mathrm{Pb}, \mathrm{Mn}, \mathrm{Ni}$, $\mathrm{Ti}$ and $\mathrm{Cu}$ concentrations decreased in soil depth columns amended with $34.8 \mathrm{~g} / \mathrm{kg}$ of compost except in the middle depth compared to control columns. The reasons were plant uptake of those metals through root organ with the addition of sludge compost; moreover, the compost could bind the metals through complexes formation which made them unavailable and non-detectable by machine (ICP). Stated that the distribution of metals in amended soil profile at different depths was relatively little and the downward movement of metals could occur in the short term of application.

Regarding the irrigation rate $(60 \mathrm{ml} / \mathrm{min})$, it had contributed towards soil metals presence, especially the barium metal, and manifested that original source of all metals was the soil because of the presence of titanium in all columns; but it was not available in the compost samples. As the soil sample gets drier the work of the extract solution would be enhanced so as to be able to extract those metals more easily. The metals were present in compost samples and amended and unamended soil samples in different quantities, but their concentrations were varying in different soil depths. $\mathrm{Al}, \mathrm{Cr}$, $\mathrm{Fe}, \mathrm{Pb}, \mathrm{Mn}, \mathrm{Ni}, \mathrm{Ti}$ and $\mathrm{Cu}$ concentrations were more with compost rates of $17.4 \mathrm{~g}$ and $34.8 \mathrm{~g} / \mathrm{kg}$, but in control columns, they were less because more water increased the availabilities of metals in amended columns whereas a lot more bound metals were released from compost and the soil material owing to the high irrigation rate but the metals were leaching in control columns when the same irrigation rate of $120 \mathrm{ml} / \mathrm{min}$ was applied (Table 3).

Table 3: The influence of compost and irrigation rates on metals concentration with soil depths columns in line 1 and line 2.

\begin{tabular}{|c|c|c|c|c|c|c|c|c|c|c|c|c|c|c|c|c|c|c|c|c|c|c|}
\hline Rote & N & Bo & $\theta$ & $C 0$ & $2 \pi$ & $\mathrm{Fe}$ & $\mathrm{PB}$ & $\mathrm{Mn}$ & NI & $\pi$ & 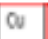 & Rate & Al & or & Co & $2 n$ & $\mathrm{Fe}$ & PD & Mn & N & $\mathrm{Cu}$ & $\mathrm{Ti}$ \\
\hline 111710 & 787.2 & 0.45 & 14.32 & 3.25 & 3.86 & 41783 & 2.82 & 79.19 & 746 & 30.03 & 191 & $12 C_{10}$ & 0.05 & 0.01 & 0.74 & ND & 154.04 & 1.03 & 5.76 & 35.34 & 2.16 & 0.34 \\
\hline 411720 & 988 & $\mathrm{No}$ & 9.16 & 1.36 & 1.56 & 802.5 & 2.45 & 41.21 & 52.13 & 11.18 & 201 & $12 C 20$ & 0.31 & 0.02 & 5.82 & 5.43 & 1907.85 & 1.55 & 47.15 & 75.99 & 18.6 & 28.77 \\
\hline 411730 & 258.0 & ND & 19.15 & 3.11 & 2.07 & $18 \mathrm{~B}$ & 2.16 & sont & 81.74 & 1201 & 297 & $12 C 30$ & 0.17 & 0.02 & 5.86 & 1.39 & 1105.7 & 0.94 & 1053 & 89.45 & 15.05 & 25.98 \\
\hline
\end{tabular}

\begin{tabular}{|c|c|c|c|c|c|c|c|c|c|c|c|c|c|c|c|c|c|c|c|c|c|c|}
\hline REA & Al & 8 & ar & 60 & $2 \pi$ & $\mathrm{k}$ & 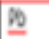 & $m$ & $\mathrm{~N}$ & $\pi$ & $\omega$ & Rate & Al & $\mathrm{Cr}$ & Co & $2 n$ & $\mathrm{Fe}$ & $\underline{P b}$ & $\mathrm{Mn}$ & Ni & $\mathrm{Cu}$ & $\pi$ \\
\hline 11610 & 497 & 0.35 & 37.2 & 4.73 & $36 !$ & 78.6 & 292 & 5155 & 12063 & 11.5 & 3.7 & 210 & 130.4 & 6.49 & ND & ND & 71.16 & 0.1 & 8.16 & 19.06 & ND & 1.3 \\
\hline $11<20$ & (4.1) & $N D$ & 1351 & 328 & 0.69 & 81.6 & 15 & 46 & $42 \pi$ & 2892 & 238 & L2 1720 & 130 & 11.35 & 0.1 & 0.39 & 563.54 & 0.46 & 12.48 & 30.39 & 3.7 & 4.56 \\
\hline 11030 & 014 & 0.2 & 17,00 & 35 & 28 & 80.5 & 259 & 34 & 108 & 2423 & 351 & 730 & 139.6 & 8.43 & 1.08 & 2.41 & 1154.98 & 2.07 & 9.54 & 44.24 & 6.64 & 8.98 \\
\hline
\end{tabular}

\begin{tabular}{|c|c|c|c|c|c|c|c|c|c|c|c|c|c|c|c|c|c|c|c|c|c|c|}
\hline REZO & N & 目 & $a$ & 60 & $2 n$ & fo & De & $\underline{\text { Nn }}$ & $\mathrm{N}$ & $\pi$ & $a$ & Rate & Al & Cr & 60 & $2 n$ & Fe & $\mathrm{pb}$ & $\mathrm{Mn}$ & Ni & $\mathrm{Cu}$ & Ti \\
\hline 11340 & 41.9 & ND & 7.98 & ND & 253 & 15.37 & 156 & 2437 & 1293 & 6.53 & No & 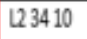 & 1256 & 4.11 & ND & ND & 709.54 & 1.17 & 27.78 & 25.74 & 9.44 & 47.69 \\
\hline 113420 & 984.3 & 1.33 & 40.8 & 388 & 533 & 9649 & 3.16 & IISI & 160.14 & 4!.21 & 3.4 & 123420 & $\$ 2.3$ & 27.19 & 6.22 & 5.23 & 2454.57 & 0.96 & 39.57 & \begin{tabular}{|l|}
151.2 \\
\end{tabular} & 11.55 & 19.93 \\
\hline 113430 & 465.4 & ND & 996 & No & 222 & 20013 & IS! & 31.09 & 41.84 & 13.3. & 10 & 3430 & 592.1 & 6.41 & 0.5 & 1.24 & 1528.51 & 1.44 & 30.37 & 33.96 & 23.76 & 19.06 \\
\hline
\end{tabular}

\begin{tabular}{|c|c|c|c|c|c|c|c|c|c|c|c|c|c|c|}
\hline \multirow{2}{*}{ Samples } & \multicolumn{14}{|c|}{ Elements Concentration $(\mathrm{mg} / \mathrm{kg}$ ) } \\
\hline & $\mathrm{Al}$ & $\mathrm{Ba}$ & $\mathrm{Cr}$ & Co & $\mathrm{Zn}$ & $\mathrm{Fe}$ & $\mathrm{Pb}$ & $\mathrm{Mn}$ & $\mathrm{Ni}$ & $\mathrm{Cu}$ & $\mathrm{B}$ & $\mathbf{p}$ & $\mathrm{Ca}$ & $\mathrm{Mg}$ \\
\hline Kala 1 & 6.35 & 1.85 & 2.65 & 3 & 3.4 & 29.5 & 7.7 & 5.35 & 0.65 & 8 & 22.6 & 125.3 & 778.5 & 149.55 \\
\hline Kala 2 & 5.25 & 1.95 & 2.1 & 3.4 & 3.15 & 27.25 & 9.1 & 4.1 & 0.45 & 5.8 & 16 & 80.4 & 731.75 & 153.85 \\
\hline Kala 3 & 4.9 & 1.95 & 1.75 & 3.2 & 0.05 & 19.7 & 6.4 & 0 & 0 & 0 & 0 & 16.35 & 709.25 & 150.85 \\
\hline
\end{tabular}

\section{Conclusion}

The article has laid stress on the application of biosolid waste (sewage sludge compost) to agricultural land to improve production.
This is a fruitful way to manage waste, taking into consideration the safety aspect and economic advantage. The hypothesis of this study was based on several theories by a host of researchers who 
have confirmed the influence of sewage sludge compost addition on the physic-chemical properties of soil and plant uptake and the availability of metal fraction in calcareous soil. The sludge compost addition could affect soil properties. It could decrease $\mathrm{pH}$ and moisture content of soil sample with irrigation rates of $60 \mathrm{ml} / \mathrm{min}$ and $120 \mathrm{ml} / \mathrm{min}$. Electrical conductivity and organic content rose with both irrigation rates and sludge compost as it went down in soil column depths. So, it is good to work with low irrigation rate $(60 \mathrm{ml} / \mathrm{min})$ to observe the influence of sludge compost addition on soil properties at different soil depths.

Omani soil is categorized as carbonated soil due to the availability of carbonate compounds which can retain metals and high levels of $\mathrm{pH}$ (alkaline soil). This makes the metals unavailable for plant uptake. Sequential extraction procedure cannot extract all metals in their different forms. However, it shows that metals are bound as metals carbonates like Mg carbonate, Calcium carbonate or Aluminum carbonate and the same metals were associated to $\mathrm{Fe}$ Mn oxide. Regard organic fraction were obvious with metals which are available in large amounts like $\mathrm{Ca}, \mathrm{Mg}$ and $\mathrm{Al}$ and trace metals like $\mathrm{Zn}, \mathrm{Ni}, \mathrm{Na}$ and it was recorded with control column.

The rest of the metals do not appear in any form except Ba (Barium) which tends to appear as exchangeable in the first depth of soil sample amended with compost $34.8 \mathrm{~g} / \mathrm{kg}$. So, high application rate of Kala compost with regular application could contribute to the liberation of the heavy metal with time. But in Oman, soil will take time for that to happen due to low water availability (3.09\%), water scarcity and less rain (precipitation) for irrigation of the land and less organic content in Omani soil (3.23\%). Irrigation rate plays an important role in the availability of heavy metals fractions. Irrigation rate of $60 \mathrm{ml} / \mathrm{min}$ has showed all types of fractions, but $120 \mathrm{ml} / \mathrm{min}$ has showed only carbonate and Fe-Mn oxide fractions. It can therefore be concluded that a high irrigation rate can increase metals leaching with time.

\section{Recommendation}

More studies and research are required for metal fractionation in order to know the various forms of metals when soil is amended with sewage sludge compost. Both experimental rates have showed fractions for metals like $\mathrm{Ca}, \mathrm{Al}$ and $\mathrm{Mg}$ which are integral components of soil. Moreover, organic fractions appeared with other metals like $\mathrm{Zn}, \mathrm{Ni}$ and $\mathrm{Na}$. It is also important to study the grass grown on Area IV at the Agricultural Experimental Station because of nickel concentration and accumulation of metals in the root zone.

\section{References}

1. Shao-qi Z, Wei-dong L, Xiao Z (2010) Effect of heavy metals on planting watercress in kailyard soil amended by adding compost of sewage sludge. Science direct, Process safety and environmental protection 88(4): 263-268.

2. Planquart P, Bonin G, Prone A, Massiani C (1999) Distribution, movement and plant availability of trace metals in soils amended with sewage sludge composts: application to low metal loadings. The science of the total environment 241(1-3): 161-179.

3. Mora MT, Echeverria JC, Garrido JJ (2000) Mobility of heavy metals in soil amended with sewge sludge. Can J soil Science 241: 161-179.

4. Plassard F, Winiarski T, Petit-Ramel M (2000) Retention and distribution of three heavy metals in a carbonated soil: comparison between batch and unsaturated column studies. 42(2-4): 99-111

5. Pinamonti F, Stringari G, Gasperi F, Zorzi G (1997) The use of compost: its effects on heavy metal level in soil and plants. Resources, conservation and recycling 21(2): 129-143.

6. Khaled EM (2004) Distribution of different Fractions of heavy metals in Desert sandy soil amended with composted sewage sludge. International Conf on water Resources \&Arid Environment.

7. Walter I, Cuevas G (1999) Chemical fractionation of heavy metals in a solid amended with repeated sewage sludge application. International journal the science of the total environment 226(2,3): 113-119. 